\title{
Effect of Y Distribution on the Oxidation Kinetics of NiCoCrAIY Bond Coat Alloys
}

\author{
T. J. Nijdam • W. G. Sloof
}

Received: 16 April 2007/Revised: 5 October 2007/Published online: 22 December 2007

(C) The Author(s) 2007

\begin{abstract}
The relation between the $\mathrm{Y}$ distribution in the alloy and the growth kinetics of the developing oxide scale was studied for the thermal oxidation of two $\mathrm{Ni}-20 \mathrm{Co}-19 \mathrm{Cr}-24 \mathrm{Al}-0.2 \mathrm{Y}$ (at.\%) alloys at 1,373 K: (i) a coarse-grain cast alloy with large $\mathrm{Ni}_{5} \mathrm{Y}$ intermetallic precipitates, and (ii) a fine-grain freestanding coating with small $\mathrm{Ni}_{5} \mathrm{Y}$ precipitates. Using a combination of experiments and model calculations, it is shown that the average growth kinetics of a NiCoCrAlY alloy are dependent on the size and distribution of Y-rich oxide inclusions (pegs) in the $\alpha-\mathrm{Al}_{2} \mathrm{O}_{3}$ oxide layer. Alumina scales containing a high density of small Y-oxide inclusions grow faster than $\alpha-\mathrm{Al}_{2} \mathrm{O}_{3}$ scales containing only a few, large Y-oxide inclusions. Upon oxidation of the freestanding coating, the Y-oxide inclusions in the scale attain their maximum size after the $\mathrm{Y}$ in the coating is completely consumed. After this point, a decrease in the average oxidation kinetics occurs.
\end{abstract}

Keywords Oxidation - Diffusion $\cdot$ Modeling $\cdot$ Alumina $\cdot$ MCrAlY bond coating

\section{Introduction}

High-temperature-coating systems, used in gas turbine engines, usually consist of a ceramic thermal barrier coating (TBC) on top, an intermediate metallic-bond coating (BC) and a superalloy substrate [1-5]. For the TBC usually yttria-stabilized zirconia (YSZ) is used. As bond coating either a Pt-modified Ni aluminide or a MCrAlY alloy $(\mathrm{M}=\mathrm{Ni}$ and/or $\mathrm{Co})$ is applied. During service, a thermally

T. J. Nijdam · W. G. Sloof

Netherlands Institute for Metals Research, Mekelweg 2, 2628 CD Delft, The Netherlands

T. J. Nijdam · W. G. Sloof $(\bowtie)$

Department of Materials Science and Engineering, Delft University of Technology,

Mekelweg 2, 2628 CD Delft, The Netherlands

e-mail: w.g.sloof@tudelft.nl 
grown oxide layer (TGO), develops between the TBC and the $\mathrm{BC}$. The TGO is predominantly comprised of $\alpha-\mathrm{Al}_{2} \mathrm{O}_{3}$ and provides protection of the underlying substrate against high-temperature corrosion. However, upon cooling of the component from high temperature, thermal-mismatch strains can develop within the TGO [5]. The elastic energy associated with these strains is the main driving force for failure of the coating system [5]. This strain energy increases with increasing TGO thickness. This explains that the failure of a high-temperature system can often be correlated with a critical TGO thickness at failure [6-8]. Thus, knowledge about the rate at which the TGO grows during service is necessary to predict the life span of the entire coating system.

The growth rate of a TGO scale is usually described with a simple parabolic rate law, since, the rate-limiting process in the growth of the oxide layer is generally the solid-state diffusion of anions and/or cations through the developing oxide layer $[9,10]$. For the oxide scales developing on the Pt-modified Ni-aluminide bond coatings, parabolic growth kinetics usually apply $[8,11]$. However, for the oxide scales developing on a MCrAlY bond coating, the growth kinetics cannot be described with a single parabolic rate constant, in particular when long oxidation periods are considered [12].

The fact that the oxide scales on MCrAlY alloys are not pure $\alpha-\mathrm{Al}_{2} \mathrm{O}_{3}$, but also contain Y-rich oxide inclusions [13-18] may explain this deviation from parabolic growth kinetics. When the reactive element $\mathrm{Y}$ from the MCrAlY alloy becomes incorporated as Y-rich oxide inclusions in the $\alpha-\mathrm{Al}_{2} \mathrm{O}_{3}$ scale, localized enhanced growth of the alumina around the $\mathrm{Y}$ inclusions occurs, resulting in the formation of protrusions (pegs) at the oxide/metal $(\mathrm{O} / \mathrm{M})$ interface. The size and density of these protrusions along the $\mathrm{O} / \mathrm{M}$ interface depends on the distribution and the reservoir of the $\mathrm{Y}$ in the alloy $[16,17,19]$. This implies that when interpreting the oxidation kinetics of a MCrAlY alloy, the initial amount and distribution of the $\mathrm{Y}$ in the alloy have to be considered.

In this work, the relation between the $\mathrm{Y}$ distribution in the alloy and the growth kinetics of the developing oxide scale was investigated for the oxidation of a NiCoCrAlY alloy. To this end, the microstructures and growth kinetics of the oxide scales developing on two Ni-20Co-19Cr-24Al-0.2Y (at.\%) alloys with different $\mathrm{Y}$ distribution were determined at $1,373 \mathrm{~K}$. The experimental results are discussed with aid of a recently developed oxide-layer growth model that takes into account the effect of reactive-element-oxide inclusions on the growth rate of protective oxide scales [20].

\section{Experimental Procedures}

A cast $\mathrm{Ni}-20 \mathrm{Co}-19 \mathrm{Cr}-24 \mathrm{Al}-0.2 \mathrm{Y}$ (at.\%) alloy and a free-standing $\mathrm{Ni}-20 \mathrm{Co}-19 \mathrm{Cr}-$ 24Al-0.2Y coating, as deposited by electron-beam, physical-vapor deposition (EB-PVD), were prepared as described in Refs. [21, 18]. Disc-shaped specimens with a diameter of $15 \mathrm{~mm}$ and thicknesses of $2 \mathrm{~mm}$ for the cast alloy and $1 \mathrm{~mm}$ for the EB-PVD coating were cut using spark erosion. Next, both alloy surfaces were ground using a Buehler SiC paper with grit 1200 as the final step. Prior to oxidation, 
all specimens were thoroughly cleaned with isopropanol and dried by blowing with compressed nitrogen.

Isothermal-oxidation experiments were preformed for 1,25 and $100 \mathrm{~h}$ at a temperature of $1,373 \mathrm{~K}$ and a partial oxygen pressure of $10^{5} \mathrm{~Pa}(1 \mathrm{~atm}$.). The experiments were executed in a horizontal alumina tube furnace (Lenton PTF 16/75/ 610 ; inner diameter $75 \mathrm{~mm}$ ) with pure oxygen passing through the furnace at a controlled flow rate of $1 \mathrm{l} / \mathrm{min}$. Specimens were inserted into the furnace as rapidly as possible to minimize oxidation upon heating. After oxidation, specimens were transported quickly out of the furnace and allowed to cool in ambient air.

The cyclic-oxidation experiments were conducted in a furnace containing four ceramic tubes at the National Aerospace Laboratory (NLR, Marknesse, The Netherlands). For each alloy, three specimens were subjected to the following thermal cycles in laboratory air: 9 minutes heating, $45 \mathrm{~min}$ hot dwell at 1,373 $\mathrm{K}$, and $10 \mathrm{~min}$ cooling (after $10 \mathrm{~min}$ the temperature was below $373 \mathrm{~K}$ ). For each alloy, one of the three specimens was withdrawn from the test after 380 cycles. The other two specimens were tested up to 1,000 cycles, after which the test was stopped. Prior to cycling and after a certain number of cycles, the mass of each alloy (i.e. net mass change) was measured using a microbalance (accuracy $\sim 10 \mu \mathrm{g}$ ). The resulting mass-change data were averaged for each alloy and subsequently normalized with respect to specimen area.

After oxidation and examination of the oxide-surface morphology, oxide/alloy cross-sections were prepared using the procedure described in Ref. [22]. To reveal the oxide-layer microstructure in more detail, selected areas (with a size of about $0.5 \times 0.5 \mathrm{~mm}$ ) of the cross-sections were fine-polished by ion milling using a JEOL SM 09010 cross-section ion polisher [23]. To this end, a $5 \mathrm{kV}$ Ar ion beam was employed.

Scanning-electron microscopy (SEM) was employed to determine the morphology and thickness of the oxide scales, the size of the Y-rich oxides in the scale, as well as the microstructure changes in the underlying alloys as a function of oxidation time (see section "Modeling and Data Analysis"). Energy-dispersive X-ray spectroscopy (EDXS) in combination with electron-backscatter-diffraction (EBSD) analysis was used to determine the phase constitution at selected points in the oxide scale. For this purpose, a JEOL JSM 6500F microscope was used, equipped with an Autrata [24] detector for observation of backscatter-electron (BSE) images, a Noran Pioneer $30 \mathrm{~mm}^{2} \mathrm{Si}(\mathrm{Li})$ detector for EDXS analysis, and a HKL Nordlys detector for the recording of electron-backscatter patterns (EBSP). The magnification of the microscope was calibrated such that the error in the length scale was less than $1 \%$. The processing of the X-ray spectra and the EBSP was performed with a ThermoNoran Vantage system (version 2.3) and the HKL Technology Channel 5 (version 5.9) software, respectively.

\section{Microstructural Observations}

Prior to oxidation, both alloys have a multiphase microstructure, consisting of precipitates of the Al-rich $\beta$-NiAl phase in a matrix of the $\mathrm{Al}$ poor $\gamma-\mathrm{Ni}$ phase 
(Fig. 1). The main difference between the microstructures of the two alloys is the size of the $\beta$ precipitates (Fig. 1). The cast alloy contains much larger $\beta$ precipitates than the EB-PVD coating. Besides a difference in $\beta$ precipitate size, the alloys also exhibited a different distribution of Y. The reason for this is that the solubility of $\mathrm{Y}$ in NiCoCrAlY alloys is very low [15]. Electron-microprobe measurements indicate the solubility of Y in the two alloys was less than 0.02 at.\% [21] (the detection limit of our electron-probe micro analyzer). Due to its low solubility, the Y was mostly confined within $\mathrm{Ni}_{5} \mathrm{Y}$ precipitates along phase and/or grain boundaries in the alloy (as identified by X-ray diffraction [21]). The size of these $\mathrm{Ni}_{5} \mathrm{Y}$ precipitates depends on the phase and/or grain-boundary density in the alloy. Thus, the $\mathrm{Ni}_{5} \mathrm{Y}$ precipitates are much larger for the coarse-grain (low density of these boundaries) cast alloy than for the fine-grain (high density of these boundaries) EB-PVD coating.

Upon isothermal and cyclic oxidation, a double-layered oxide scale developed on both alloys, consisting of a thin, porous layer near the oxide surface and a thick, columnar-grain layer near the oxide/metal interface (Fig. 2). The thickness of the outer oxide layer was independent of the oxidation times studied, indicating that the oxide products in this layer were formed during initial oxidation (i.e. transient oxidation [25-27]). The transient oxide products were not identified, since this was not a focus of this study. The inner oxide layer in both cases consisted of $\alpha-\mathrm{Al}_{2} \mathrm{O}_{3}$ (as identified by EBSD) and Y-rich oxide inclusions (Fig. 2). According to EDXS and EBSD analysis, two types of Y-rich oxides were formed (see inserts in Fig. 2): (i) a cubic oxide almost exclusively made up of $\mathrm{Y}$ and $\mathrm{O}$, and (ii) a cubic oxide containing similar amounts of $\mathrm{Y}$ and $\mathrm{Al}$ next to $\mathrm{O}$. Based on these results, it is concluded that the former is made up of $\mathrm{Y}_{2} \mathrm{O}_{3}$, while the latter is cubic $\mathrm{YAlO}_{3}$ (i.e. with ideal perovskite structure). In some cases, a single oxide inclusion was composed of a core of $\mathrm{Y}_{2} \mathrm{O}_{3}$ surrounded by a sheath of $\mathrm{YAlO}_{3}$ (see Fig. 2d). This result indicates that the $\mathrm{YAlO}_{3}$ formed due to a solid-state reaction between $\mathrm{Y}_{2} \mathrm{O}_{3}$ and $\alpha-\mathrm{Al}_{2} \mathrm{O}_{3}$.
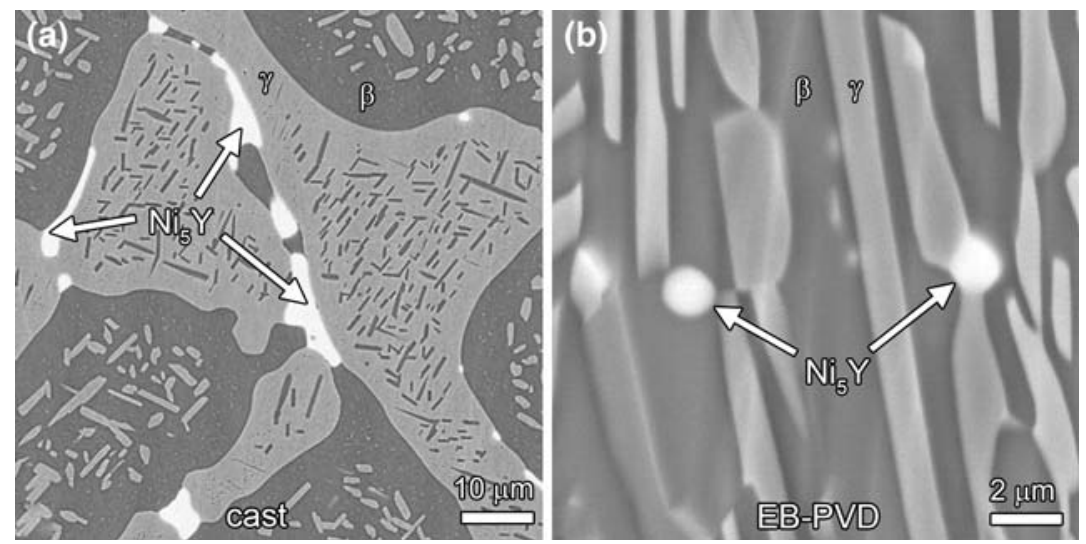

Fig. 1 Backscatter-electron images of the microstructures of the (a) cast and (b) EB-PVD Ni-20Co$19 \mathrm{Cr}-24 \mathrm{Al}-0.2 \mathrm{Y}$ alloy prior to oxidation. Notice the difference in magnification 

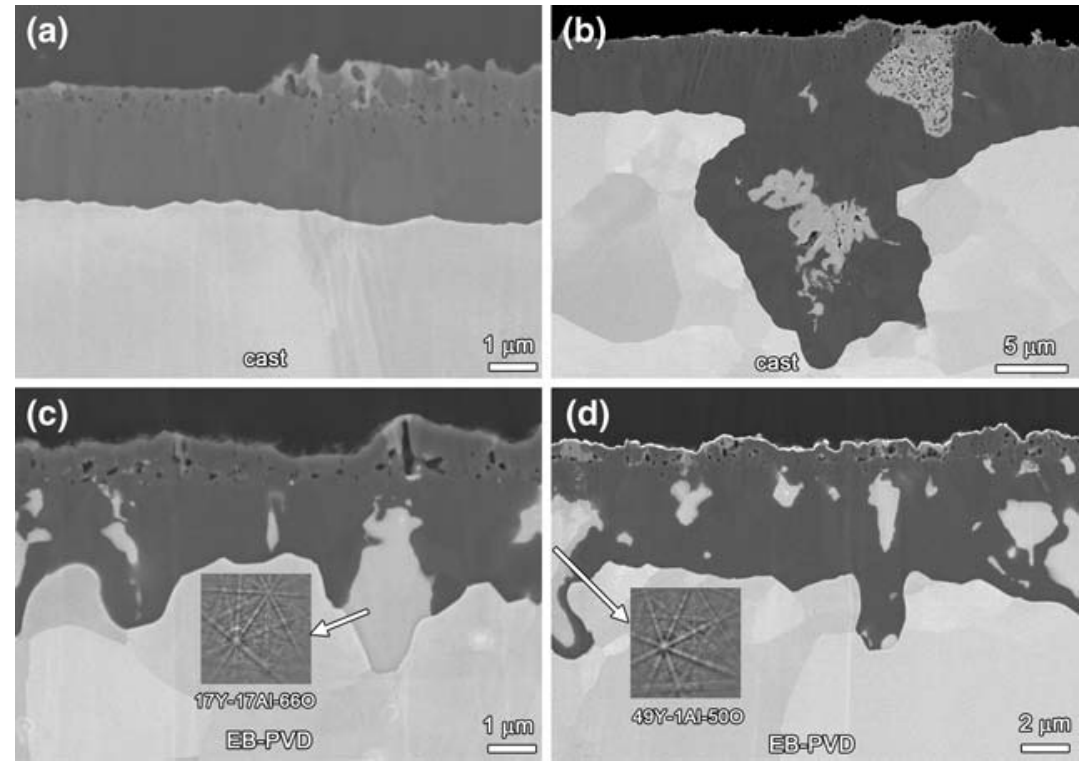

Fig. 2 Backscatter-electron images of the oxide/alloy cross-sections of the (a, b) cast, and (c, d) EB-PVD Ni-20Co-19Cr-24Al-0.2Y alloy after oxidation at 1,373 K. (a, c) $25 \mathrm{~h}$ isothermal oxidation, (b) $750 \mathrm{~h}$ cyclic oxidation, and (d) $285 \mathrm{~h}$ cyclic oxidation. The inserts show the compositions and electron backscatter patterns of the two indicated Y-rich oxide inclusions

The incorporation of the Y-rich oxide inclusions in the scale leads locally to enhanced growth of the oxide scale and consequently to a roughening of the oxide/ metal interface. Clearly, the $\mathrm{O} / \mathrm{M}$ interface is relatively smooth at those locations where Y-rich oxides are absent in the scale (Fig. 2a), and relatively rough at those positions where Y-rich oxide inclusions are present in the scale (Fig. 2b-d). The formation of these so-called protrusions (or pegs) at the $\mathrm{O} / \mathrm{M}$ interface is a commonly observed phenomenon for the oxidation of MCrAlY alloys [17, 28] and coatings [13-16]. Close inspection of the location of the Y-rich oxide inclusions revealed that for both alloys almost all inclusions were formed above alloy grain or phase boundaries (Fig. 2), in agreement with previous reports [13, 17, 28, 29]. In some samples, internal oxidation of $\mathrm{Y}$ in advance of the $\mathrm{O} / \mathrm{M}$ interface was observed, but the total amount of internally oxidized $\mathrm{Y}$ was very small compared with the amount of Y oxides within the scale.

Finally, the incorporation of $\mathrm{Y}$ as oxide inclusions in the scale leads to a depletion of the $\mathrm{Y}$ from the coating. As is clearly shown in Fig. 3, oxidation leads to a formation of an almost uniform zone free of $\mathrm{Ni}_{5} \mathrm{Y}$ precipitates in the alloy region adjacent to the $\mathrm{O} / \mathrm{M}$ interface.

\section{Modeling and Data Analysis}

A model was developed for describing the effect of Y-rich oxide inclusions on the oxidation kinetics of MCrAlY coating alloys. A schematic illustration of this model, 
Fig. 3 Backscatter-electron images of the microstructure of the (a) cast and (b) EB-PVD Ni20Co-19Cr-24Al-0.2Y alloy after $25 \mathrm{~h}$ of isothermal oxidation at $1,373 \mathrm{~K}$. The bright spots correspond to the $\mathrm{Ni}_{5} \mathrm{Y}$ precipitates
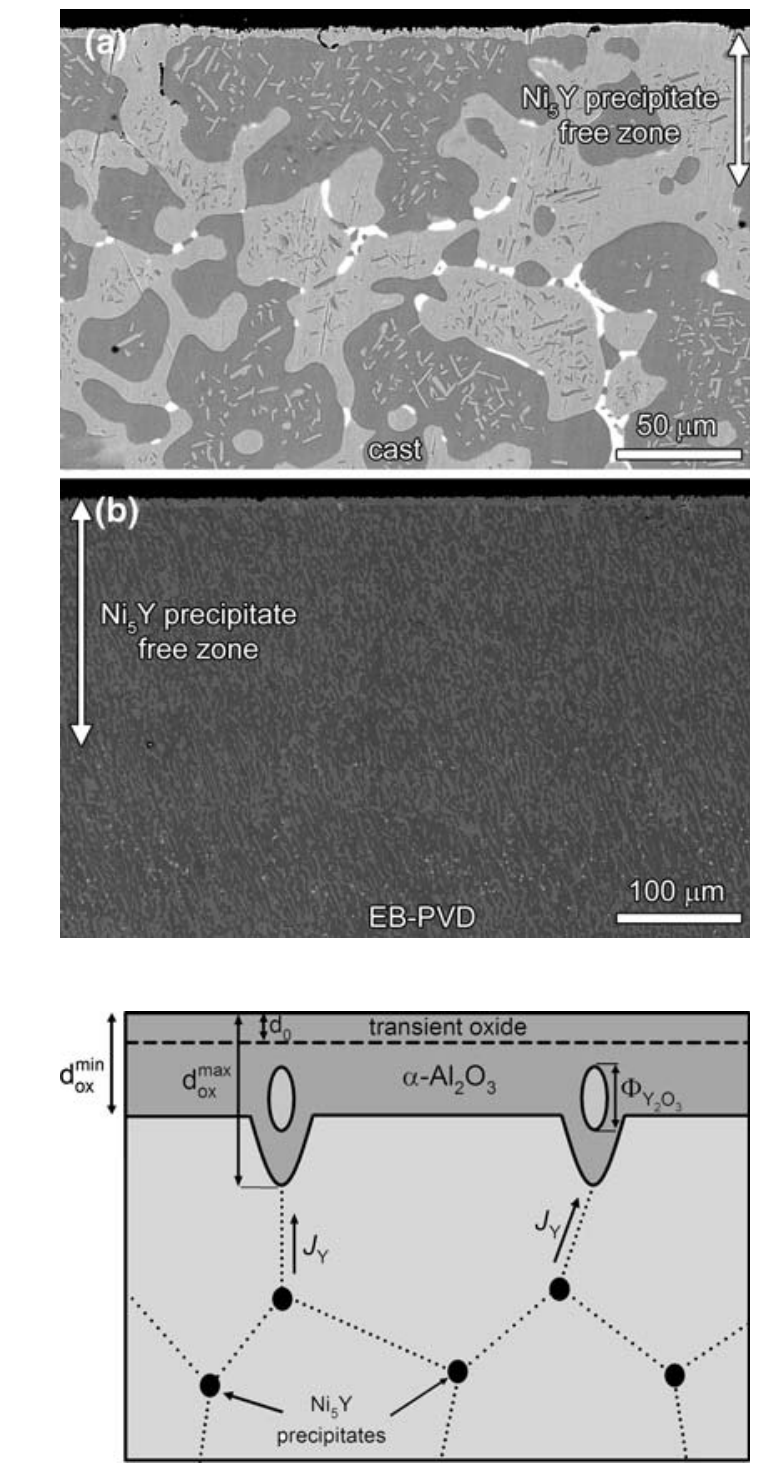

Fig. 4 Schematic illustration of the model used to determine the effect of the Y oxide inclusions on the growth kinetics of the NiCoCrAlY alloys

for which the details are provided in Ref. [20], is given in Fig. 4. The model was based on the following considerations:

(i) Following a short transient oxidation stage, the oxide scale forming between the protrusions consists solely of $\alpha-\mathrm{Al}_{2} \mathrm{O}_{3}$. This alumina scale grows according to parabolic oxidation kinetics and is further referred to as the minimum oxidescale thickness $d_{\mathrm{ox}}^{\mathrm{min}}$.

(ii) Above each alloy phase or grain boundary one protrusion (or peg) is formed. The thickness of the scale above the alloy grain boundaries is denoted as the 
maximum oxide-scale thickness $d_{\mathrm{ox}}^{\max }$. The value of $d_{\mathrm{ox}}^{\max }$ is taken equal to the value of $d_{\mathrm{ox}}^{\mathrm{min}}$ plus the amount of $\mathrm{Y}_{2} \mathrm{O}_{3}\left(\Phi_{\mathrm{Y}_{2} \mathrm{O}_{3}}\right)$ within a single protrusion. Thus, the $\mathrm{Y}_{2} \mathrm{O}_{3}$ inclusions do not affect the growth rate of the alumina scale.

(iii) The amount of $\mathrm{Y}_{2} \mathrm{O}_{3}$ within a protrusion is taken equal to the maximum amount of $\mathrm{Y}$ that can be supplied by dissolution and diffusion of $\mathrm{Y}$ from $\mathrm{Ni}_{5} \mathrm{Y}$ precipitates along alloy grain or phase boundaries to the oxide/metal interface during a given oxidation period.

(iv) The average oxide-scale thickness $\left\langle d_{\mathrm{ox}}\right\rangle$ is considered to be a linear combination of scale thicknesses in between and on top of the alloy grain or phase boundaries (i.e. the values of $d_{\mathrm{ox}}^{\min }$ and $d_{\mathrm{ox}}^{\max }$ ).

The model was applied to the oxidation of the cast and the EB-PVD Ni-20Co$19 \mathrm{Cr}-24 \mathrm{Al}-0.2 \mathrm{Y}$ alloys at $1,373 \mathrm{~K}$. To calculate the oxidation kinetics of the two alloys, the following data are required: the molar volume of the alloy, the molar volume of $\mathrm{Y}_{2} \mathrm{O}_{3}$, the parabolic rate constant of $\alpha-\mathrm{Al}_{2} \mathrm{O}_{3}$, the boundary diffusion coefficient of $\mathrm{Y}$ in the alloy, the $\mathrm{Y}$ content in the alloy, the solubility of $\mathrm{Y}$ in the alloy, the size of the $\beta$ precipitates and the size of the $\mathrm{Ni}_{5} \mathrm{Y}$ precipitates in the alloy. The values for these data for the oxidation of the two NiCoCrAlY alloys at 1,373 K are given in Table 1.

In order to verify the model calculations, for both alloys, the minimum, average and maximum oxide-scale thickness, the amount of yttria within a protrusion and the depth of the $\mathrm{Ni}_{5} \mathrm{Y}$-precipitate-free zone were also determined from experiment. For the determination of the $\mathrm{Ni}_{5} \mathrm{Y}$-precipitate-free zone, the amount of $\mathrm{Y}_{2} \mathrm{O}_{3}$ within a protrusion and the minimum- and maximum-scale thickness, as can be seen in Fig. 4, were determined from backscatter-electron images for at least 25 positions along the $\mathrm{O} / \mathrm{M}$ interface. For the determination of the average oxide-layer thickness, five BSE images were converted into grayscale images for each alloy. Then the

Table 1 Data used for the calculations. The data apply to the oxidation of a Ni-20Co-19Cr-24Al-0.2Y (at.\%) alloy at $1,373 \mathrm{~K}$

\begin{tabular}{|c|c|c|c|}
\hline Symbol & Value & Unit & Remarks \\
\hline Molar volume alloy & 7.0 & $\mathrm{~cm}^{3} / \mathrm{mol}$ & Taken from Ref. [30] \\
\hline Molar volume $\mathrm{Y}_{2} \mathrm{O}_{3}$ & 44.9 & $\mathrm{~cm}^{3} / \mathrm{mol}$ & Taken from Ref. [31] \\
\hline Molar volume $\mathrm{Al}_{2} \mathrm{O}_{3}$ & 25.6 & $\mathrm{~cm}^{3} / \mathrm{mol}$ & Taken from Ref. [31] \\
\hline $\mathrm{Y}$ content in alloy & 0.2 & at. $\%$ & Measured with EPMA \\
\hline Y solubility in alloy & 0.01 & at. $\%$ & $\begin{array}{l}\text { Half of the EPMA detection } \\
\text { limit }\end{array}$ \\
\hline Y boundary diffusion coefficient & $5 \times 10^{-8}$ & $\mathrm{~cm}^{2} / \mathrm{s}$ & Fit parameter \\
\hline Parabolic rate constant $\alpha-\mathrm{Al}_{2} \mathrm{O}_{3}$ & $4.2 \times 10^{-13}$ & $\mathrm{~g} / \mathrm{cm}^{4} \mathrm{~s}$ & Taken from Ref. [32] \\
\hline Specimen thickness & 0.4 (EB-PVD) 2.0 (cast) & $\mathrm{mm}$ & $\begin{array}{l}\text { Measured after surface } \\
\text { preparation }\end{array}$ \\
\hline Size of $\beta$ precipitates in alloy & 1.5 (EB-PVD) 40 (cast) & $\mu \mathrm{m}$ & $\begin{array}{l}\text { Measured from BSE images } \\
\text { (Fig. 3) }\end{array}$ \\
\hline Size of $\mathrm{Ni}_{5} \mathrm{Y}$ precipitates & 1 (EB-PVD) 3 (cast) & $\mu \mathrm{m}$ & $\begin{array}{l}\text { Measured from BSE images } \\
\text { (Fig. 3) }\end{array}$ \\
\hline
\end{tabular}


average oxide-layer thickness was taken equal to the number of pixels belonging to the oxide scale divided by the total number of pixels in the image and multiplied by the height of the image.

\section{Results and Discussion}

The experimental and calculated evolution of the minimum, maximum and average oxide-layer thickness for both alloys as function of oxidation time is shown in Fig. 5. Good agreement exists between the experiments and the model calculations.

On the surfaces of both alloys, a continuous, columnar-grain $\alpha-\mathrm{Al}_{2} \mathrm{O}_{3}$ layer formed between the protrusions (Fig. 2). The generally accepted mechanism for the growth of such an alumina layer is the inward diffusion of oxygen along oxide grain boundaries $[33,34]$. If diffusion through the scale is rate-limiting, the experimental growth kinetics can usually be described with a parabolic growth law [9, 10]. Thus, provided that the oxide scales developed between the protrusions do not have different microstructures, for both alloys the growth kinetics should be parabolic and the parabolic rate constant describing the evolution of the minimum oxide-layer thickness should be similar. Indeed, the experimental results for the minimum oxide-layer thickness are well described with the same parabolic rate constant if the transient oxidation period is taken into account (Fig. 5).

Fig. 5 Experimentally determined and calculated minimum, maximum and average oxide-layer thickness as function of oxidation time for the oxidation of the (a) cast, and (b) EB-PVD NiCoCrAlY coating at $1,373 \mathrm{~K}$. The data points up to $100 \mathrm{~h}$ of oxidation were determined from isothermal-oxidation experiments, the data points at $285 \mathrm{~h}$ and $750 \mathrm{~h}$ of oxidation were determined from thermalcycling tests

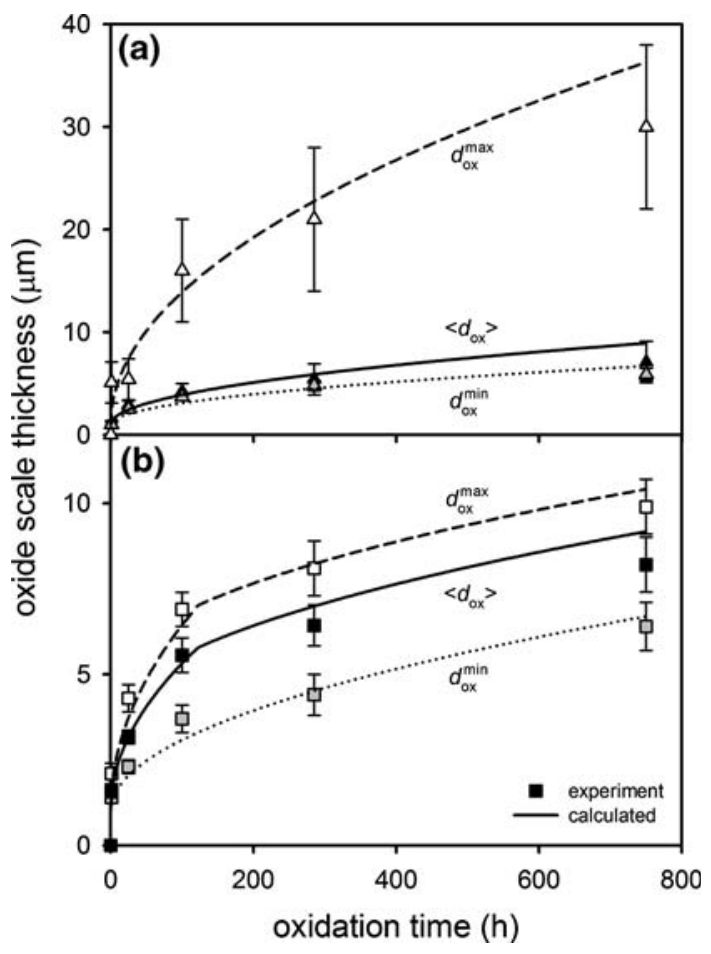


In the size evolution of the protrusions, considerable differences were observed for the two alloys. Clearly, the maximum oxide-layer thickness is much smaller for the EB-PVD coating (Fig. 5b). This is attributed to the fact that the EB-PVD coating contains a high density of grain and phase boundaries at which small $\mathrm{Ni}_{5} \mathrm{Y}$ precipitates are present (Figs. $1 \mathrm{~b}$ and $3 \mathrm{~b}$ ). Subsequent oxidation leads to the formation of a high density of Y-oxide inclusions in the scale, but only with a small penetration of the oxide scale into the alloy (Figs. 2c and d). For the cast alloy, on the other hand, the $\mathrm{Ni}_{5} \mathrm{Y}$ precipitates are much larger, and therefore the penetration of the oxide scale into the alloy is much deeper (Figs. 2b and 5a). However, due to the large size of the $\beta$ precipitates, the distance between two protrusions in the cast alloy is much larger than that of the EB-PVD coating (Fig. 2b).

Like the minimum oxide-layer thickness, the maximum oxide-layer thickness also shows a parabolic evolution with oxidation time (Fig. 5). The reason for this is that the supply of Y from the alloy towards the oxide scale (i.e. the dissolution of Y from the $\mathrm{Ni}_{5} \mathrm{Y}$ precipitates) is controlled by diffusion and thus proportional to the square root of oxidation time (Fig. 6a). For the EB-PVD coating, a transition in the growth kinetics of the protrusions can be observed (Fig. 5b). Clearly, after about $100 \mathrm{~h}$ of oxidation, the size of the protrusion increases much slower than before this point. This transition from fast to slow kinetics is attributed to the total depletion of $\mathrm{Ni}_{5} \mathrm{Y}$ precipitates from the EB-PVD coating (Fig. 6a). The complete disappearance of the $\mathrm{Ni}_{5} \mathrm{Y}$ precipitates from the coating is associated with a maximum in the size of the Y oxide inclusions in the scale (Fig. 6b). For the cast alloy, no total depletion

Fig. 6 Experimentally determined and calculated (a) depth of the $\mathrm{Ni}_{5} \mathrm{Y}$ precipitatefree zone as function of oxidation time, and (b) amount of $\mathrm{Y}_{2} \mathrm{O}_{3}$ within a single peg as a function of oxidation time, for the oxidation of the cast and EB-PVD NiCoCrAlY alloys at $1,373 \mathrm{~K}$. The data points up to $100 \mathrm{~h}$ of oxidation were determined from isothermaloxidation experiments, the data points at $285 \mathrm{~h}$ and $750 \mathrm{~h}$ of oxidation were determined from a thermal-cycling test

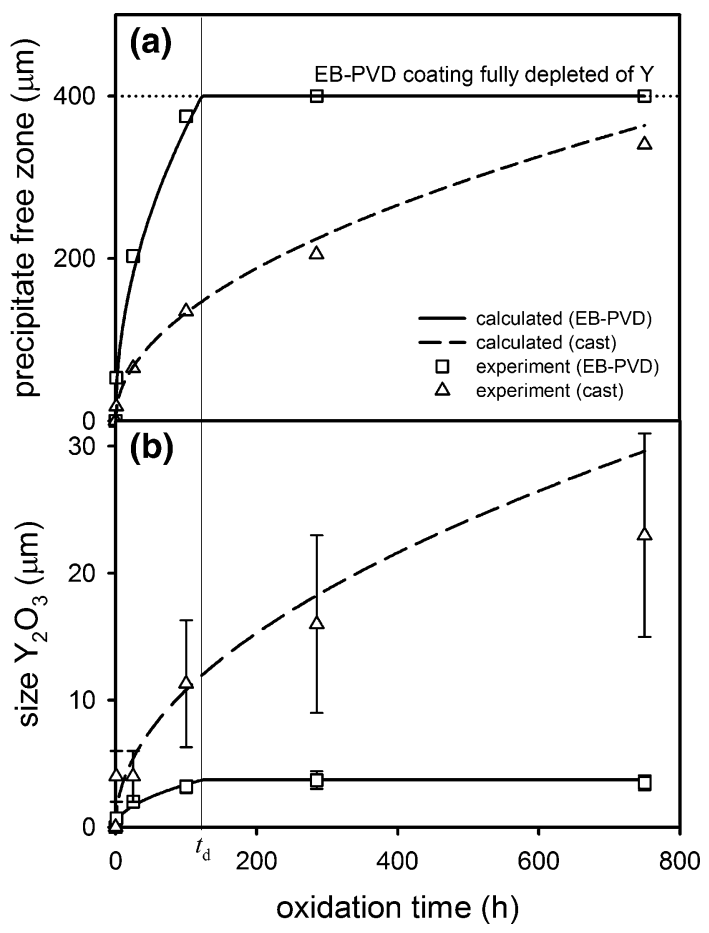


of $\mathrm{Y}$ occurred and thus no transition in the growth kinetics of the protrusions was observed. This is attributed to the use of a thicker specimen for the cast alloy $(2 \mathrm{~mm}$ as compared to $1 \mathrm{~mm}$ for the EB-PVD coating) and a slower rate at which the $\mathrm{Ni}_{5} \mathrm{Y}$ precipitate-free zone thickens (Fig. 6a). The latter is an effect of the larger size of the $\mathrm{Ni}_{5} \mathrm{Y}$ precipitates in the cast alloy (Fig. 1).

The average oxide-layer growth kinetics are a combination of the oxidation kinetics between and on top of the alloy grain/phase boundaries (see section "Modeling and Data Analysis"). Thus, the average oxide-scale growth rate is determined by the values for the minimum and maximum oxide-layer thickness, as well as the distance between two alloy grain/phase boundaries. Experimental and calculated average oxide-layer growth kinetics in terms of specimen mass gain for the cast alloy and the EB-PVD coating are shown in Fig. 7. Clearly, on average the EB-PVD coating oxidizes faster than the cast alloy when oxidized under the same conditions (i.e. temperature and oxygen partial pressure). This difference in scale growth rate is solely determined by the difference in $\mathrm{Y}$ distribution in the two alloys, since both alloys form a continuous $\alpha-\mathrm{Al}_{2} \mathrm{O}_{3}$ layer with similar amounts of transient oxidation op top of the alloy phases (Fig. 2). Thus, on a NiCoCrAlY alloy, an oxide scale containing a high density of small $\mathrm{Y}$ oxide inclusions grows faster than an oxide scale containing only a few, large $\mathrm{Y}$ oxide inclusions.

For the oxidation of MCrAlY alloys, our present results have the following implications. First, the average growth kinetics of the scale developing on a MCrAlY alloy will always be faster than that of a pure alumina scale, as long as Y-rich-oxide inclusions become incorporated in the scale. Only after the $\mathrm{Y}$ in the coating has been completely consumed, the oxidation rate of a MCrAlY alloy can be described solely by the parabolic rate constant of $\alpha-\mathrm{Al}_{2} \mathrm{O}_{3}$. Next, the oxidation kinetics of a MCrAlY coating depend on the microstructure of the coating, i.e. Y distribution, and the specimen thickness, i.e. Y reservoir. This is in agreement with previous observations [16, 17]. Finally, if the $\mathrm{Y}$ in the coating becomes totally depleted (a phenomenon which will always occur when thin coatings are applied), a transition in the oxidation kinetics will occur. This may explain why the experimental growth kinetics of a MCrAlY coating [12] cannot be described with a single parabolic rate constant.

Fig. 7 Experimentally determined and calculated weight change as function of oxidation time for the oxidation of cast and the EB-PVD

NiCoCrAlY alloy at $1,373 \mathrm{~K}$. The calculated data represent the isothermal oxidation kinetics, the experimental data are results from a thermal-cycle test up to the point where oxide spallation was first observed

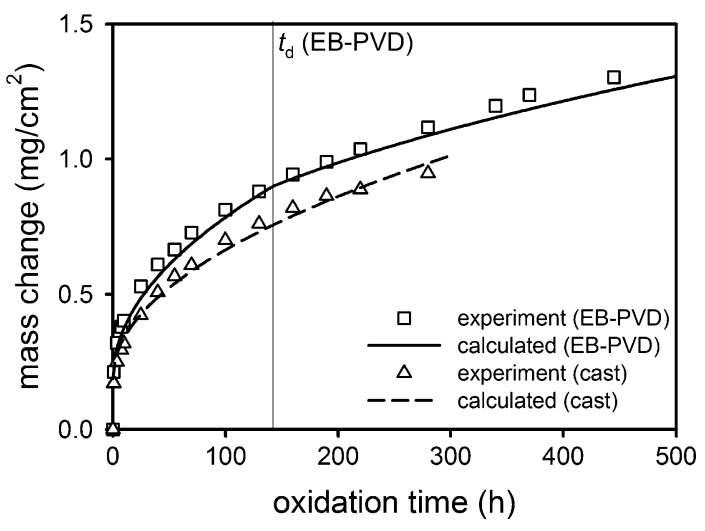




\section{Conclusions}

The relation between the $\mathrm{Y}$ distribution in the alloy and the growth kinetics of the developing oxide scale was studied for the thermal oxidation of two Ni-20Co19Cr-24Al-0.2Y (at.\%) alloys at 1,373 K: (i) a coarse grain cast alloy with large $\mathrm{Ni}_{5} \mathrm{Y}$ intermetallic precipitates, and (ii) a fine-grain freestanding coating with small $\mathrm{Ni}_{5} \mathrm{Y}$ precipitates. Upon isothermal and cyclic oxidation, on both alloys a doublelayered oxide developed, consisting of a transient outer layer and an $\alpha-\mathrm{Al}_{2} \mathrm{O}_{3}$ inner layer containing $\mathrm{Y}_{2} \mathrm{O}_{3}$ and $\mathrm{YAlO}_{3}$ inclusions (pegs). On top of the coarse-grain cast alloy, only a few, very large pegs formed, whereas on top of the fine-grain freestanding coating a high density of small pegs developed.

It was shown that the average growth kinetics of an oxide scale with Y-rich oxide inclusions is faster than the growth kinetics of an oxide scale consisting of pure $\alpha-\mathrm{Al}_{2} \mathrm{O}_{3}$. The evolution of the growth kinetics depends on the size and distribution of $\mathrm{Y}$ oxide inclusions in the $\alpha-\mathrm{Al}_{2} \mathrm{O}_{3}$ layer. The NiCoCrAlY alloy oxidizes faster if the developing alumina scale contains a high density of small $\mathrm{Y}$ oxide inclusions. For a thin coating, the $\mathrm{Y}$ oxide inclusions in the scale attain their maximum size after the $\mathrm{Y}$ in the coating is completely consumed. After this point, a decrease in the average oxidation kinetics occurs. This implies that the oxidation rate of a MCrAlY alloy is affected by the specimen thickness.

Acknowledgments This research was carried out under project number MC7.04186 in the framework of the Strategic Research program of the Netherlands Institute for Metals Research in the Netherlands (www.nimr.nl). The authors are indebted to Dr. Ir. A.B. Kloosterman at NLR for thermal cycling testing.

Open Access This article is distributed under the terms of the Creative Commons Attribution Noncommercial License which permits any noncommercial use, distribution, and reproduction in any medium, provided the original author(s) and source are credited.

\section{References}

1. N. P. Padture, M. Gell, and E. H. Jordan, Science 296, 280 (2002).

2. J. R. Nicholls, MRS Bulletin 28, 659 (2003).

3. M. Peters, C. Leyens, U. Schulz, and W. A. Kaysser, Advanced Engineering Materials 3, 193 (2001).

4. M. J. Stiger, N. M. Yanar, M. G. Topping, F. S. Pettit, and G. H. Meier, Zeitschrift für Metallkunde 90, 1069 (1999).

5. A. G. Evans, D. R. Mumm, J. W. Hutchinson, G. H. Meier, and F. S. Pettit, Progress in Materials Science 46, 505 (2001).

6. V. K. Tolpygo, D. R. Clarke, and K. S. Murphy, Surface and Coatings Technology 146-147, 124 (2001).

7. T. J. Nijdam, G. H. Marijnissen, E. Vergeldt, A. B. Kloosterman and W. G. Sloof, Oxidation of Metals 66, 269 (2006).

8. I. T. Spitsberg, D. R. Mumm, and A. G. Evans, Materials Science and Engineering A 394, 176 (2005).

9. P. Kofstad, High Temperature Corrosion (Elsevier Applied Science, London and New York, 1988), p. 162.

10. N. Birks, G. H. Meier, and F. S. Pettit, Introduction to the High Temperature Oxidation of Metals, 2nd ed. (Cambridge university press, Cambridge, 2006), p. 39. 
11. S. Sridharan, L. Xie, E. H. Jordan, M. Gell, and K. S. Murphy, Materials Science and Engineering A 393, 51 (2005).

12. U. Schulz, M. Menzebach, C. Leyens, and Y. Q. Yang, Surface and Coatings Technology 146-147, 117 (2001).

13. D. R. Mumm and A. G. Evans, Acta Materialia 48, 1815 (2000).

14. J. A. Haynes, M. K. Ferber, W. D. Porter, and E. D. Rigney, Oxidation of Metals 52, 31 (1999).

15. D. P. Whittle, D. H. Boone, and I. M. Allam, Thin Solid Films 73, 359 (1980).

16. J. Toscano, R. Vassen, A. Gil, M. Subanovic, D. Naumenko, L. Singheiser, and W. J. Quadakkers, Surface and Coatings Technology 201, 3906 (2006).

17. T. J. Nijdam, C. Kwakernaak, and W. G. Sloof, Metallurgical and Materials Transactions 37A, 683 (2006).

18. T. J. Nijdam, L. P. H. Jeurgens, J. H. Chen, and W. G. Sloof, Oxidation of Metals 64, 357 (2005).

19. H. Hindam and D. P. Whittle, Journal of the Electrochemical Society 129, 1147 (1982).

20. T. J. Nijdam and W. G. Sloof, Acta Materialia 55, 5980 (2007).

21. C. Kwakernaak, T. J. Nijdam, and W. G. Sloof, Metallurgical and Materials Transactions 37A, 695 (2006).

22. T. J. Nijdam, L. P. H. Jeurgens, and W. G. Sloof, Acta Materialia 53, 1643 (2005).

23. M. Shibata, JEOL news 39, 28 (2004).

24. R. Autrata, P. Schauer, J. Kvapil, and J. Kvapil, Journal of Physics E: Scientific Instruments 11, 707 (1978).

25. C. G. Levi, E. Sommer, S. G. Terry, A. Catanoiu, and M. Rühle, Journal of the American Ceramic Society 86, 676 (2003).

26. D. Clemens, V. Vosberg, L. W. Hobbs, U. Breuer, W. J. Quadakkers, and H. Nickel, Fresenius Journal of Analytical Chemistry 355, 703 (1996).

27. D. Clemens, V. R. Vosberg, H. J. Penkalla, U. Breuer, W. J. Quadakkers, and H. Nickel, Fresenius Journal of Analytical Chemistry 358, 122 (1997).

28. R. Munoz-Arroyo, D. Clemens, F. Tietz, R. Anton, J. Quadakkers, and L. Singheiser, Materials Science Forum 369-372, 165 (2001).

29. C. Mennicke, M.-Y. He, D. R. Clarke, and J. S. Smith, Acta Materialia 48, 2941 (2000).

30. K. A. Khor and Y. W. Gu, Materials Science and Engineering A 277, 64 (2000).

31. O. Kubaschewski and B. E. Hopkins, Oxidation of Metals and Alloys, 2nd ed. (Butterworths, London, 1962), p. 8 .

32. M. W. Brumm and H. J. Grabke, Corrosion Science 33, 1677 (1992).

33. R. Prescott and M. J. Graham, Oxidation of Metals 38, 233 (1992).

34. F. H. Stott, G. C. Wood, and J. Stringer, Oxidation of Metals 44, 113 (1995). 